\title{
Progressive hemiparesis due to spino-laminar anomaly of the axis-a case report and literature review
}

\author{
Srivijayanand K. $\mathbf{S}^{1} \cdot$ Ankith Naduvanahalli Vivekanandaswamy ${ }^{1} \cdot$ Ajoy Prasad Shetty ${ }^{1} \cdot$ Rishi Mugesh Kanna $^{1}$. \\ Shanmuganathan Rajasekaran ${ }^{1}$
}

Received: 5 March 2019 / Revised: 10 July 2019 / Accepted: 14 July 2019

(c) International Spinal Cord Society 2019

\begin{abstract}
Introduction Some of the most common developmental malformations of the axis include anomalies of the odontoid, for example, hypoplasia or aplasia. Isolated anomalies of the posterior arch of the axis rarely occur. This study reports a unique case of congenital anomaly of the neural arch of the axis vertebra, which manifested clinically as progressive hemiparesis. Case presentation A 33-year-old man presented with progressive weakness of the right upper and lower limbs that had lasted 18 months. The patient reported loss of right-hand dexterity in the 6 months period before he consulted us. Plain radiographs, computed tomography (CT), and magnetic resonance imaging (MRI) revealed C5-C6 block vertebra, primary canal stenosis and spino-laminar anomaly of the axis, along with invagination of the lamina into the canal causing severe cord compression.

Discussion The anomalous posterior element of the axis was excised, and the cord was decompressed. The presence of congenital stenosis and block vertebrae at the C5-C6 level necessitated decompression and instrumentation between C2-C6. Simultaneous occurrence of a posterior arch anomaly, primary canal stenosis, and block vertebra has not been previously described. A cervical spine anomaly presenting as hemiparesis is uncommon in clinical practice. Information enabling clinicians to identify causative anomaly and determine the appropriate surgical intervention is useful, and can facilitate a good clinical outcome.
\end{abstract}

\section{Introduction}

Congenital anomalies of the axis often involve malformations of the odontoid process; in contrast, anomalies of the posterior arch are rare. The abnormalities may range from a simple cleft in the posterior arch to complete absence of the arch. Congenital anomalies of the cervical spine usually present with deformity, myelopathy, and occasionally as an incidental finding on radiographs. This study discusses a unique case with a $\mathrm{C} 2$ spino-laminar posterior arch defect that presented with progressive hemiparesis.

Ajoy Prasad Shetty

ajoyshetty@gmail.com

1 Department of Spine Surgery, Ganga Hospital, 313, Mettupalayam road, Coimbatore, India

\section{Case presentation}

A 33-year-old right-handed male presented with progressive weakness of the right upper and lower limbs for the last 18 months along with associated numbness in the right arm, trunk, and leg. The patient developed gait instability, and loss of right-hand dexterity for the last 6 months, before he was seen at our hospital. There was no bowel or bladder dysfunction, trauma, or neck pain. The patient's brain was evaluated using magnetic resonance imaging (MRI) with angiogram, which showed no abnormality. The cervical spine was normal with no noticeable tenderness, and all neck movements were pain free. Neurological examination revealed hypertonia on the right side with motor weakness (grade 3/5) in the right deltoid, biceps, and quadriceps muscle (C4 AIS D). There was wasting of the intrinsic hand muscles with grade $3 / 5$ power in wrist flexors, extensors and the finger flexors on the right side. Tibialis anterior, extensor hallucis longus and the toe flexors had grade 5/5 power. The deep tendon reflexes of the knee and ankle were brisk with extensor plantar response on the right side. The 
right upper extremity showed a positive Hoffman's sign. Even though the patient had numbness in the right upper and lower limbs, sensory examination for posterior column (fine touch, vibration, proprioception) and spinothalamic tract (crude touch, pain, temperature) did not reveal any abnormality and a sensory level could not be established. Similarly no abnormality could be found on the cranial nerves examination. The patient received a score of 12 on the modified Japanese Orthopedic Association scale (mJOA) scale, signifying moderate myelopathy [1]. Upon further investigation, plain radiographs revealed a spinolaminar anomaly of axis, with no atlanto-axial instability on dynamic films, and block vertebrae at C5-C6 (Fig. 1). Computed tomography (CT) also clearly demonstrated an anomalous spino-laminar process with bilateral laminar invagination into the spinal canal, the presence of congenital cervical canal stenosis with an anteroposterior diameter of $10 \mathrm{~mm}$ from $\mathrm{C} 2$ to $\mathrm{C} 5$, and associated $\mathrm{C} 5-\mathrm{C} 6$ block vertebrae (Fig. 2). MRI demonstrated ventrally displaced C2 lamina and spinous process impinging on the cord, with $\mathrm{T} 2$ hyper-intense signal changes extending from $\mathrm{C} 2$ to $\mathrm{C} 3$. It also showed degenerated discs with spondylotic changes at $\mathrm{C} 3-\mathrm{C} 4$ and $\mathrm{C} 4-\mathrm{C} 5$, which further accentuated the primary canal stenosis (Fig. 3).
Fig. 1 Plain radiographs showing a spino-laminar anomaly on anteroposterior view (white arrow). Lateral Dynamic view radiographs showing displacement of anomalous spino-laminar process into the canal during extension (black arrow)
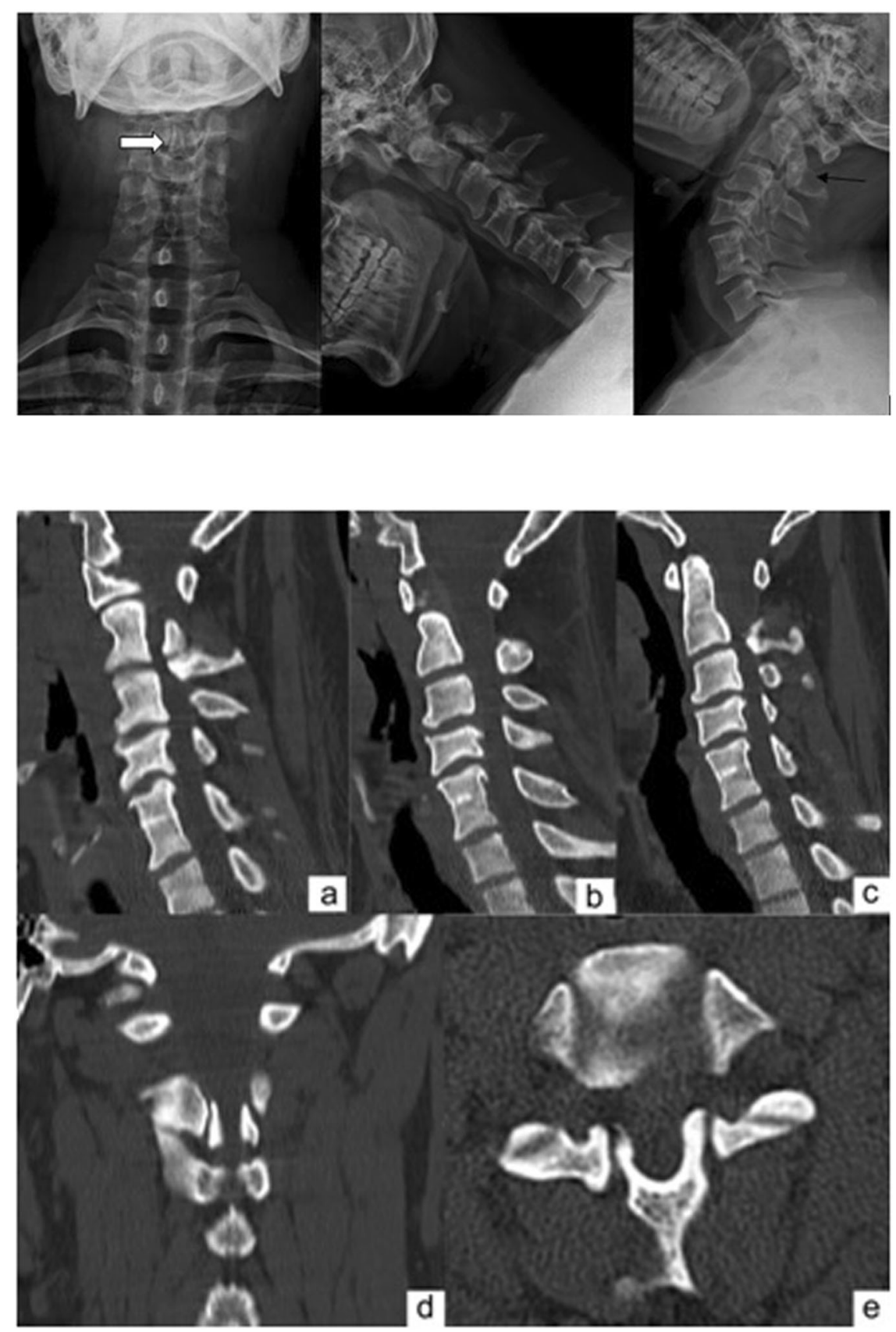

Fig. 2 CT sagittal images (a-right sagittal, b-mid sagittal, c-left sagittal) showing congenital cervical stenosis and C5-C6 block vertebrae. Coronal and axial images

(d, e) show a posterior defect of axis at lamino-facetal junction, sclerosed edges of lamina which invaginates into the canal 
Fig. 3 MRI para-sagittal (a, c) and mid-sagittal image (b) showing $\mathrm{T} 2$ hyper intensity changes extending from $\mathrm{C} 2-\mathrm{C} 3$ and cord compression due to invaginated laminar process (d) of axis evident on axial images. Also note the canal stenosis at C3-C4, C4-C5 levels (e, f)
Fig. 4 Post operative radiographs $(\mathbf{a}, \mathbf{b})$ of patient showing C2-C6 posterior Instrumentation
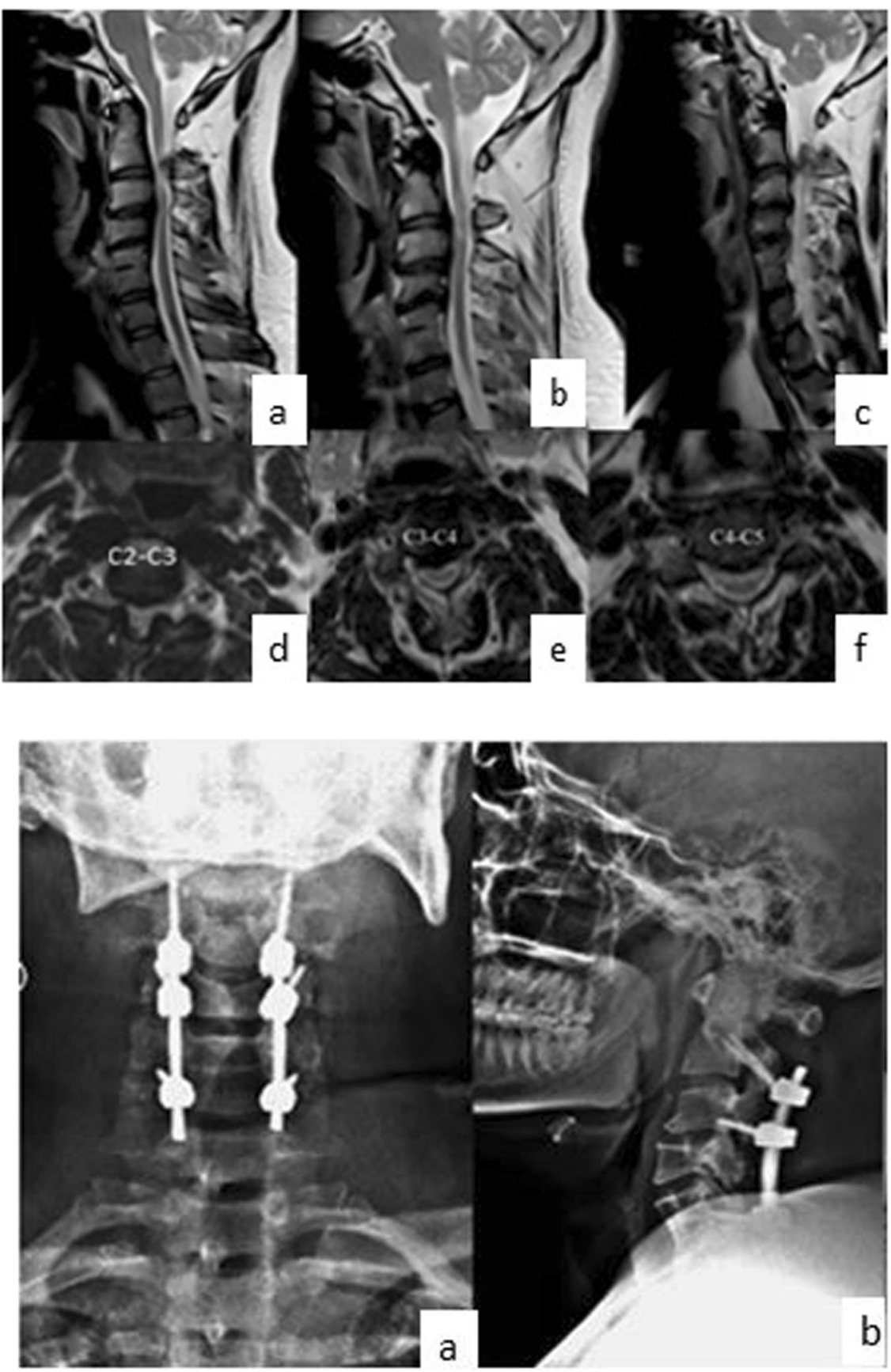

The patient was subjected to excision of the anomalous spino-laminar process of $\mathrm{C} 2$ along with the removal of intervening fibrous tissue. In view of the primary canal stenosis and the C5-C6 block vertebrae with multilevel degenerated discs, C2-C6 laminectomy and instrumented fusion was performed with $\mathrm{C} 2$ pars screws and, lateral mass screws in the sub-axial cervical spine. Adequate decompression of the cord was achieved, and the intraoperative and post-operative course was uneventful. The patient was ambulatory with a cervical orthosis within 1 day after surgery (Fig. 4). At the1-year follow-up, the patient's gait pattern had improved and clumsiness of the hand had resolved. Neurologically, the patient had improved to 5/5 in both the right upper and lower limb (AIS E) and the mJOA score had improved to 17 . The patient was able to manage all the daily activities without any discomfort.

\section{Discussion}

Cervical myelopathy, due to affection of the sub-axial cervical spine, is common in clinical practice. Myelopathy due 
Table 1 Summary of case reports with cervical myelopathy secondary to anomaly of posterior axis

\begin{tabular}{|c|c|c|c|c|c|c|}
\hline Year & Author & Age/sex & Radiology & $\begin{array}{l}\text { Instability } \\
\text { (Yes/No) }\end{array}$ & Management & Outcome \\
\hline 1986 & Koyama et al. [5] & $54 / \mathrm{M}$ & $\begin{array}{l}\text { Spina bifida of } \mathrm{C} 2 \text {; bilateral } \\
\text { invaginated laminae of } \mathrm{C} 2\end{array}$ & No & Anomaly removed & Good \\
\hline 1999 & Asakawa et al. [6] & $46 / \mathrm{M}$ & $\begin{array}{l}\text { Spina bifida of } \mathrm{C} 2 \text {; lateral } \\
\text { invaginated bifid lamina of } \mathrm{C} 2 \text {; } \\
\text { enlarged } \mathrm{C} 3 \text { spinous process }\end{array}$ & No & $\begin{array}{l}\text { Anomaly removed }+\mathrm{C} 3 \\
\text { laminectomy }\end{array}$ & Good \\
\hline \multirow[t]{2}{*}{1999} & Goel et al. [7] & $42 / \mathrm{M}$ & $\begin{array}{l}\text { Absence of the posterior axis; } \\
\text { Dislocation of } \mathrm{C} 2 \text { over } \mathrm{C} 3\end{array}$ & Yes & $\begin{array}{l}\text { Occipito-cervical fusion } \\
\text { Reoperation: transoral C2/3 } \\
\text { decompression }\end{array}$ & $\begin{array}{l}\text { Poor } \rightarrow \\
\text { good }\end{array}$ \\
\hline & Goel et al. [7] & $16 / \mathrm{M}$ & $\begin{array}{l}\text { Complete absence of the posterior } \\
\text { axis; dislocation of } \mathrm{C} 2 \text { over } \mathrm{C} 3\end{array}$ & Yes & $\begin{array}{l}\text { Anterior decompression }+ \\
\text { Posterior Occipito-cervical fusion }\end{array}$ & Good \\
\hline 2009 & Chau et al. [8] & $14 / \mathrm{M}$ & $\begin{array}{l}\mathrm{C} 1 \text { posterior arch agenesis; } \\
\text { bilateral invaginated laminae of } \\
\mathrm{C} 2 \text {; free floating spinous process }\end{array}$ & No & $\begin{array}{l}\text { Anomaly removed + lateral mass } \\
\text { fixation at } C 2 / 3\end{array}$ & Good \\
\hline 2013 & Sakaura et.al. [9] & 68/M & $\begin{array}{l}\text { Bilaterally separated lamina with } \\
\text { Invaginated lamina of axis }\end{array}$ & No & Anomaly removed & Good \\
\hline 2016 & Moon et al. [10] & $56 / \mathrm{M}$ & $\begin{array}{l}\text { Bilateral invaginated lamina of } \\
\text { axis, absence of right pedicle and } \\
\text { spina bifida of } \mathrm{C} 7\end{array}$ & No & Anomaly removed & Good \\
\hline
\end{tabular}

The causative anomaly, presence of instability, management and outcome are shown

to affection of the upper cervical vertebrae $(\mathrm{C} 1, \mathrm{C} 2)$ is rare, and myelopathy due to involvement of the axis or at the level of C2-C3 is even rarer [2]. Development of the vertebrae occurs in three stages: precartilage, cartilage, and ossification. Failure in the development of the vertebral chondrification center of the posterior arch of a particular sclerotome, or failure of appropriate ossification, may lead to posterior arch defects, such as an absent posterior arch, spondylolysis, absent pedicle syndrome, or defective lamina. The defect in the lamina at the lamino-facetal junction in this patient might have occurred because of problems with chondrification or ossification during embryogenesis. Van Gilder et al. classified defects of the axis into defects of atlantoaxial segmentation, dens dysplasia, OS odontoideum, hypoplasia, and aplasia, and segmentation failure of $\mathrm{C} 2 / 3$ [3]. However posterior arch anomalies were not included in this classification, indicating the rarity of this condition. Structural vertebral anomalies occur sporadically, in isolation or as an accompaniment to multi-organ developmental malformations [4]. However in the present case no such associations were noted.

Posterior arch anomalies of the axis resulting in cervical myelopathy have previously been reported [5-10]. In 1986, Koyama et al. [5] were the first to describe a case of a 54year-old male with gait disturbance who had spina bifida of $\mathrm{C} 2$ and bilateral invaginated laminae of $\mathrm{C} 2$. The anomaly was successfully removed with a good post-surgical outcome. Moon et al. [10] reported a myelopathy patient with laminar cleft defect. Eight reports on myelopathy secondary to rare anomalies of the posterior arch of the axis were identified during our review of the literature [5-10].
However, all literature reported bilateral symptoms; a summary of the review is presented in Table 1 .

Myelopathy manifesting as hemiparesis with multiple abnormalities, such as spino-laminar defect, congenital stenosis, and block vertebra, in a single patient is unique. In the present case, the compression occurred more on the right side, which might explain the unilateral symptoms and the clinical findings. The clinical manifestations in the patient with unilateral motor involvement without a sensory level and contralateral sensory findings fail to qualify to be a brown sequard syndrome which is a known manifestation of cervical myelopathy. Cerebrovascular accidents primarily present with hemiparetic symptoms; however, in rare circumstances when cerebral involvement is ruled out after investigations and clinically facial nerve is spared, it is worthwhile to determine if cervical spine pathology is present.

\section{Conclusion}

Although bilateral symptoms are the most common modes of presentation in congenital cervical spine anomalies, rare encounters with atypical presentations, such as hemiparesis, can also occur in a clinician's lifetime. Simultaneous occurrence of an arch defect of the axis, block vertebra, and primary canal stenosis in the same patient makes this report very unique and useful to other clinicians.

Author contributions All authors contributed equally towards the preparation of this manuscript and we acknowledge all of their efforts. 


\section{Compliance with ethical standards}

Conflict of interest The authors declare that they have no conflict of interest.

Publisher's note: Springer Nature remains neutral with regard to jurisdictional claims in published maps and institutional affiliations.

\section{References}

1. Tetreault L, Kopjar B, Nouri A, Arnold P, Barbagallo G, Bartels $\mathrm{R}$, et al. The modified Japanese Orthopaedic Association scale: establishing criteria for mild, moderate and severe impairment in patients with degenerative cervical myelopathy. Eur Spine J. 2017;26:78-84.

2. Sakai S, Sakane M, Harada S, Kaneoka K, Amano K, Ochiai N. A cervical myelopathy due to invaginated laminae of the axis into the spinal canal. Spine. 2004;29:E82-4.

3. Vangilder JC, Menezes AH. Craniovertebral junction abnormalities. Neurosurgery. 1983;30(CN_suppl_1):514-30.
4. Passias PG, Poorman GW, Jalai CM, Diebo BG, Vira S, et al. Incidence of congenital spinal abnormalities among pediatric patients and their association with scoliosis and systemic anomalies. J Pediatr Orthop. 2019;9:343-55.

5. Koyama T, Tanaka K, Handa J. A rare anomaly of the axis: report of a case with shaded three-dimensional computed tomographic display. Surg Neurol. 1986;25:491-4.

6. Asakawa H, Yanaka K, Narushima K, Meguro K, Nose $T$. Anomaly of the axis causing cervical myelopathy: case report. J Neurosurg. 1999;91:121-3.

7. Goel A, Gupta S, Laheri V. Congenital absence of posterior elements of axis: a report of two cases. Br J Neurosurg. 1999;13:459-61.

8. Chau AM, Wong JH, Mobbs RJ. Cervical myelopathy associated with congenital $\mathrm{C} 2 / 3$ canal stenosis and deficiencies of the posterior arch of the atlas and laminae of the axis: case report and review of the literature. Spine. 2009;34:E886-91.

9. Sakaura H, Yasui Y, Miwa T, Yamashita T, Ohzono K, Ohwada T. Cervical myelopathy caused by invagination of anomalous lamina of the axis: case report. J Neurosurg. 2013;19:694-6.

10. Moon BJ, Choi KY, Lee JK. Cervical myelopathy caused by bilateral laminar cleft of the axis: case report and review of literature. World Neurosurg. 2016;93:487-e11. 